\title{
Diagnostic difficulties in patients with a pancreatic mass
}

\author{
M R Zeiderman, A Wyman, H A Euinton, J M Simms, K Rogers
}

University Department of Surgery and Department of Radiology, Northern General Hospital, Sheffield M R Zeiderman, FRCS, lecturer in surgery

A Wyman, FRCS, lecturer in surgery

H A Euinton, FRCR, consultant radiologist

K Rogers, FRCs, professor of surgery

Department of Surgery,

Chesterfield and North

Derbyshire Royal Hospital, Chesterfield

J M Simms, FRCS, consultant surgeon

\section{Correspondence to:}

Mr M R Zeiderman, Royal Hallamshire Hospital, Sheffield S10 2JF.

BMF 1991;302:1395-6

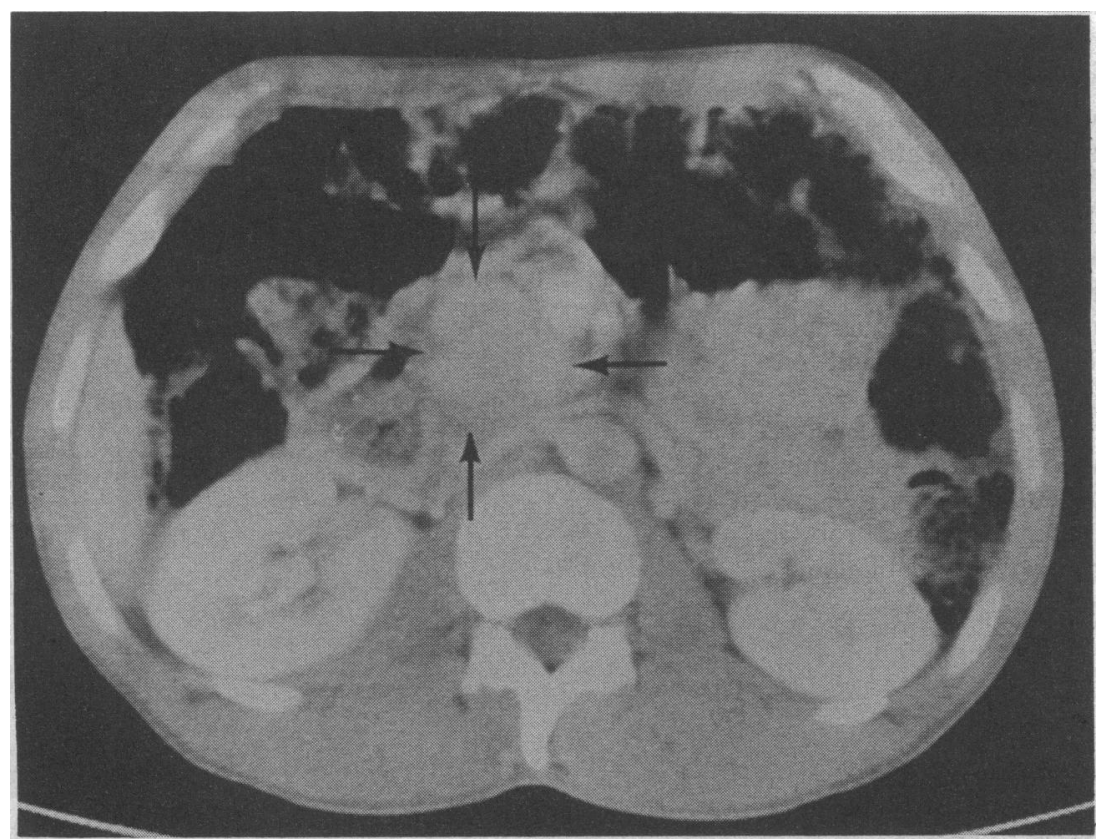

Computed tomogram of upper abdomen showing well circumscribed mass (arrowed) within head of pancreas (case 2) with pancreatic carcinoma is remote a nihilistic approach can easily be adopted. After biochemical and radiological investigation many patients with obstructive jaundice and a mass in the head of the pancreas are treated by insertion of an endoprosthesis without a tissue diagnosis. While subsequent pathological findings may concur in up to $96 \%$ of patients the following cases show that failure to make a definitive tissue diagnosis before treatment may have serious consequences for the few patients who have a potentially treatable condition or benign disease.

\section{Case 1}

A 50 year old woman was admitted with a one week history of progressive jaundice, dark urine, and pale stools. Examination showed hepatomegaly and an epigastric mass $9 \mathrm{~cm}$ in diameter. Results of biochemical investigations were as follows: haemoglobin concentration $126 \mathrm{~g} / \mathrm{l}$, white cell count $4.83 \times 10^{9} / 1$ with a normal differential, bilirubin concentration $115 \mu \mathrm{mol} / \mathrm{l}$, alkaline phosphatase concentration
Although surgery for pancreatic carcinoma offers the only hope of cure, resection is associated with a high morbidity and a perioperative mortality which in some series has been as high as $40 \%$. $^{\prime}$ In those who survive operation the outlook remains poor: more than $80 \%$ of patients with adenocarcinoma of the pancreas die within 12 months and only $1-2 \%$ survive five years. ${ }^{12}$ As resection is inappropriate for most patients internal biliary drainage with an endoprosthesis has become widely accepted as palliative treatment for malignant extrahepatic biliary obstruction, ${ }^{34}$ surgery being reserved primarily for those patients in whom the placement of an endoprosthesis is not possible or who develop duodenal obstruction.

As the possibility of prolonged survival in patients $1125 \mathrm{IU} / \mathrm{l}$, alanine aminotransferase concentration dilatation of the common bile duct (by $1 \mathrm{~cm}$ in diameter) as far as the head of the pancreas, which measured $3.8 \mathrm{~cm}$ and had a homogeneous texture. Computed tomography showed the abnormality in the head of the pancreas to be a well circumscribed mass which did not seem to be infiltrating surrounding structures (figure). Percutaneous transhepatic cholangiography showed a dilated common hepatic duct with a smooth stricture immediately below the origin of the cystic duct extending to the ampulla. The appearances were thought to be due to extrinsic compression from a pancreatic tumour, and an internal biliary endoprosthesis (Carey-Coons) was inserted. No biopsy specimen was taken.

When reviewed one month later the patient was well and without clinical or biochemical evidence of jaundice. Indeed he continued to remain well, raising doubts as to the clinical diagnosis. Repeat computed tomography six months later showed no focal lesion within the pancreas. Ten months after the initial procedure he returned with recurrent jaundice due to blockage of the endoprosthesis. A repeat ultrasound scan showed no evidence of malignant disease. At laparotomy the findings were a thickened pancreas together with patches of fat necrosis, suggesting pancreatitis. There was no evidence of malignancy. 
Because of a fibrous stricture of the common bile duct around the endoprosthesis, most marked at the confluence of left and right hepatic ducts, it was necessary to fashion a hepaticodochojejunostomy. The histological appearance of the common bile duct was consistent with a chronic inflammatory process. He made an uneventful recovery, and although his liver enzyme concentrations remained raised (alanine aminotransferase $65 \mathrm{IU} / 1$, alkaline phosphatase $612 \mathrm{IU} / \mathrm{l}$ ) he remained well 24 months later.

\section{Case 3}

An 81 year old white man presented to the outpatient clinic with a two week history of painless obstructive jaundice, having previously been well and without symptoms. Apart from a mild icterus examination was unremarkable. Results of biochemical investigations were as follows: haemoglobin concentration $114 \mathrm{~g} / 1$, white cell count $26.9 \times 10^{9} / 1\left(14.8 \times 10^{9} / 1\right.$ neutrophils, $11 \cdot 0 \times 10^{9} / 1$ lymphocytes), alkaline phosphatase concentration $1106 \mathrm{IU} / 1, \gamma$-glutamyltransferase concentration $299 \mathrm{IU} / \mathrm{l}$, bilirubin concentration $38 \mu \mathrm{mol} / \mathrm{l}$. An ultrasound scan showed a dilated intrahepatic and extrahepatic biliary tree and a mass in the head of the pancreas. A presumptive diagnosis of carcinoma of the head of pancreas was made, but when the patient was reviewed in the clinic one month later he was no longer jaundiced (bilirubin $18 \mu \mathrm{mol} / \mathrm{l}$ ), although his liver enzyme profile was still abnormal (alkaline phosphatase $833 \mathrm{IU} / 1, \gamma$-glutamyltransferase $331 \mathrm{IU} / \mathrm{l})$. A repeat ultrasound scan showed no evidence of dilated bile ducts, although the pancreatic mass persisted.

He was lost to follow up but returned 12 months later in extremis. He was profoundly cachexic but not jaundiced. Abdominal examination showed gross ascites. Results of biochemical investigations were as follows: haemoglobin concentration $97 \mathrm{~g} / 1$, white cell count $30 \cdot 1 \times 10^{9} / 1$. He died 24 hours later. At necropsy there was a dense fibrous mass around the head of the pancreas which had resulted in incomplete obstruction of the extrahepatic biliary tree. The body of the pancreas was also replaced by dense white fibrous tissue. While the right adrenal gland was not obviously enlarged the medulla had a similar macroscopic appearance to the pancreas. Histological appearances in sections taken from both the pancreas and the adrenal glands were consistent with tuberculosis. There was no evidence of pulmonary tuberculosis.

\section{Discussion}

These three cases show that an accurate diagnosis is essential in order to identify those patients with potentially curable disease. While differentiation of patients into those with benign disease and those with malignant disease on clinical and laboratory data alone may be difficult, diagnostic rates in excess of $90 \%$ have been reported from a combination of ultrasonography, percutaneous transhepatic cholangiography, and computed tomography. ${ }^{5-7}$

Diagnostic difficulties are most commonly encountered in differentiating between pancreatic carcinoma and chronic pancreatitis, particularly as the two may coexist. ${ }^{5}$ Misdiagnosis occurred in case 2 and probably accounted for the prolonged survival of patients with "malignant extrahepatic biliary obstruction" reported by others. ${ }^{8}$ Clearly what is needed to help clarify the situation is a tissue diagnosis, yet for many years clinicians have been reluctant to perform biopsy on the pancreas because they have believed that this carries an appreciable risk of bleeding, fistula formation, infection, and even death. However, much of the present day concern that surrounds pancreatic biopsy was generated over 15 years ago because of surgeons' experience of peroperative wedge or core needle biopsy. ${ }^{9}$ With the introduction of finer needles and aspiration cytology the complication rate of peroperative biopsy has been greatly reduced. ${ }^{10}$ As various diagnostic techniques for localising pancreatic lesions have become available fine needle aspiration has assumed a new dimension in the diagnosis of pancreatic malignancy. Ultrasonically guided percutaneous fine needle aspiration can yield sufficient tissue for analysis in about $80 \%$ of patients, allowing a cytological diagnosis of carcinoma in about $90 \%$ of these-an overall clinical success rate of $76 \% .^{.1}$ By using an 18 gauge needle (Tru-Cut) to obtain samples for histological examination an accurate diagnosis can be achieved in up to $94 \%$ of patients. ${ }^{12}{ }^{13}$ No false positive results have been reported, and complications are rare despite the passage of the needle through abdominal viscera.

On reviewing the notes of patients with obstructive jaundice who had presented to our hospital over the past five years a histological diagnosis was available in only $25 \%$. With modern techniques for imaging and biopsy this is no longer acceptable. Most patients thought to have inoperable pancreatic carcinoma are given an endoprosthesis; it is important to ensure that the absence of a definitive histological diagnosis does not deny some patients the chance of cure.

We thank Mr C L Welsh for permission to report case 1 .

1 Anderson JB, Cooper MJ, Williamson RCN. Adenocarcinoma of the extra-

hepatic biliary tree. Ann R Coll Surg Engl 1985;67:139-43.
2 Van Steigmann G, Bornman P, Terblanche J. Carcinoma of the pancreas at Groote Schur Hospital 1975-1979. S Afr Med f 1981;60:97-9.

3 Bornman PC, Harris-Jones EP, Tobias R, Van Steigman G, Terblanche J. Prospective controlled trial of transhepatic biliary endoprosthesis versus bypass surgery for incurable carcinoma head of pancreas. Lancet 1986;i: bypass $69-71$.

4 Shepherd HA, Royle G, Ross APR, Diba A, Arthur M, Colin-Jones D. Endoscopic biliary endoprosthesis in the palliation of malignant obstruction of the distal common bile duct: a randomized trial. Br J Surg 1988;75: 1166-8.

5 Armstrong CP, Dixon JM, Taylor TV, Davies GC. Surgical experience of deeply jaundiced patients with bile duct obstruction. Br f Surg 1984;71: 234-8.

6 Vennes JA, Bond JH. Approach to the jaundiced patient. Gastroenterology 1983;84:1615-8.

7 Matzen P, Malchow-Moller A, Brun B. Ultrasonography, computerized tomography and cholescintigraphy in suspected obstructive jaundice-a randomized study. Gastroenterology 1983;84:1492-7.

8 McLeod GG, Armstrong DN, Ross AHM, Buist TAS, Macleod IB. Management of malignant biliary obstruction by percutaneously introduced biliary ment of malignant biliary obstruction by percutaneo

9 Lightwood R, Reber HA, Way LW. The risk and accuracy of pancreatic

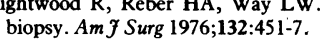

10 Christofferson P, Poll P. Peroperative pancreas aspiration biopsies. Acta Microbiologica Scandinavica 1970;212:28-32.

11 Houdenak N, Lees WR, Pereira J, Belby IOW, Cotton PB. Ultrasound guided percutaneous fine needle aspiration cytology of pancreatic mass lesions. BMJ 1982;285:1183-4.

12 Mitchell CJ, Wai D, Jackson AM, MacFie J. Ultrasound guided percutaneous pancreatic biopsy. $\mathrm{Br} \mathcal{F}$ Surg 1989;76:706-7.

13 Jaeger HJ, MacFie J, Mitchell CJ, Couse N, Wai D. Diagnosis of abdominal masses with percutaneous biopsy guided by ultrasound. BMF 1990;301: $1188-91$.

(Accepted 19 March 1991) 